\title{
ANTIBIOTIC PRODUCTION BY NEW FORM-GENERA OF THE ACTINOMYCETALES. II.
}

\section{ANTIBIOTIC A/672 ISOLATED FROM A NEW SPEGIES OF AGTINOPLANES : ACTINOPLANES BRASILIENSIS NOV. SP.}

\author{
J. E. Thiemann, G. Beretta, G. Coronelli and H. Pagani \\ Research Laboratories, Lepetit S. p. A., Milan, Italy \\ (Received for publication January 12, 1969)
}

\begin{abstract}
A new species of Actinoplanes designated as Actinoplanes brasiliensis nov. sp. is described. Its taxonomic relationship with other species of Actinoplanes as well as the cultural, physiological and biochemical characteristics, are also discussed. The antibiotic A/672 produced by the new isolate is described and its in vitro and in vivo data are given.
\end{abstract}

Reports on the antibiotic production by members of the Actinoplanaceae have been limited to the best of our knowledge, to sporaviridin ${ }^{1)}$, which can be considered as being the first antibiotic isolated from a member of the Actinoplanaceae ${ }^{2)}$, and to sporangiomycin an antibiotic produced by a member of the recently described genus Planomonospor $a^{3)}$. Literature references do exist on the in vitro antibiotic activity of members of other new genera of the Actinomycetales, however, no efforts seem to have been made for the production of these antibiotics under submerged conditions and for their isolation ${ }^{4,5,6,7)}$.

In the present paper we wish to report on the taxonomy of a new species of Actinoplanes and on the antibiotic substance A/672 produced by the same.

The isolate, which received our collection number $\mathrm{A} / 672$ was isolated from a soil sample collected in the State of Bahia (Brazil), and showed to possess antibacterial activity when grown under submerged conditions. The abundant formation, on a number of culture media, of sporangia containing highly motile sporangiospores, places this isolate squarely in the family Actinoplanaceae and in the genus Actinoplanes. The various morphological, cultural and physiological characteristics presented by strain $\mathrm{A} / 672$, permit its differentiation from the other known species of Actinoplanes, and strain A/672 is considered to be a new species for which the name Actinoplanes brasiliensis nov. sp. is proposed.

For the taxonomic characterization of strain $\mathrm{A} / 672$, the procedures described by SHIRLING and GotTLIEB ${ }^{8)}$ (supplemented by additional media recommended by WAKs$\mathrm{MAN}^{9)}$ ) were followed. For comparative purposes, the three species of Actinoplanes described by $\mathrm{CoucH}^{10,11)}$ were included in the present study.

\section{General Characteristics}

Microscopic examination of strain A/672 grown on various media showed it to be consistently devoid of aerial mycelium. This lack of aerial mycelium is a general 


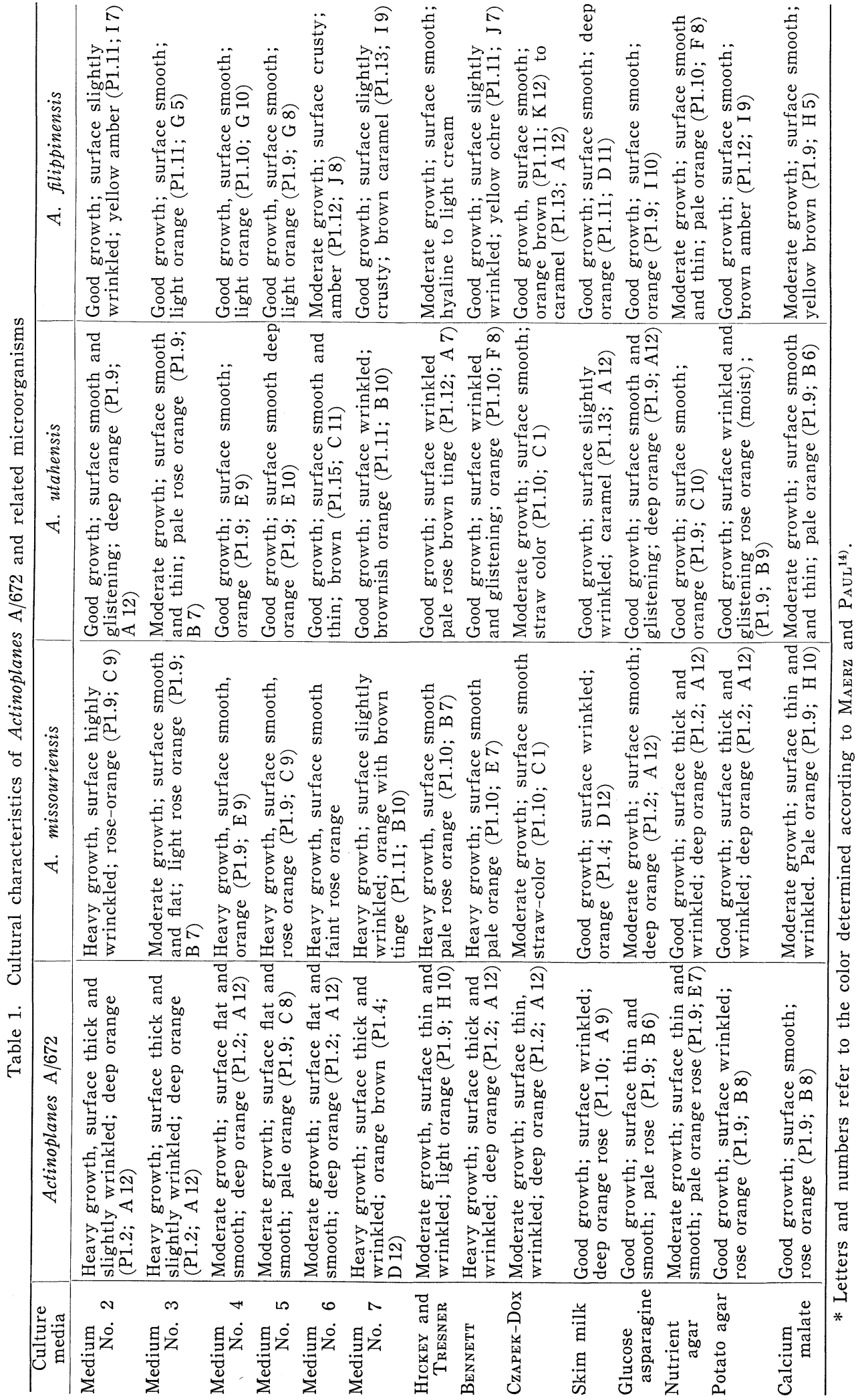


Plate 1. Actinoplanes brasiliensis. Typical umbrella-shaped sporangium. Internal differentiation of spores prior to the sporangiospore liberation noticeable $(\times 1520 \times 1 / 1.5)$

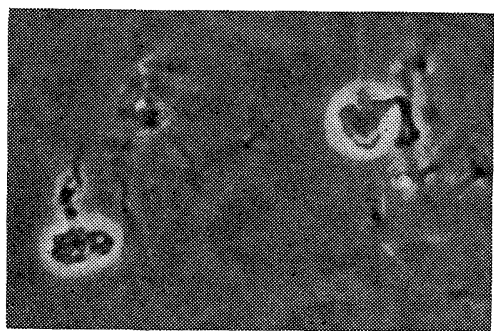

Plate 4. Actinoplanes philippinensis. Sporangia imbeded in the vegetative mycelium $(\times 520 \times 1 / 1.5)$

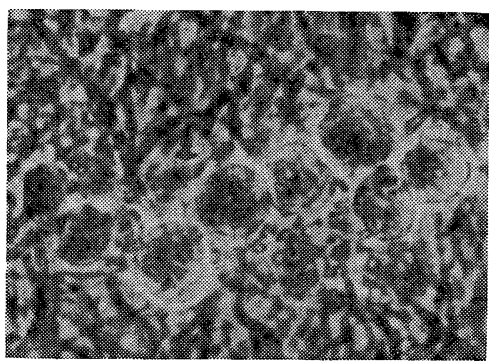

Plate 7. Actinoplanes brasiliensis. Spore liberation by means of the unoriented rupture of the sporangia $(\times 1520 \times 1 / 1.5)$

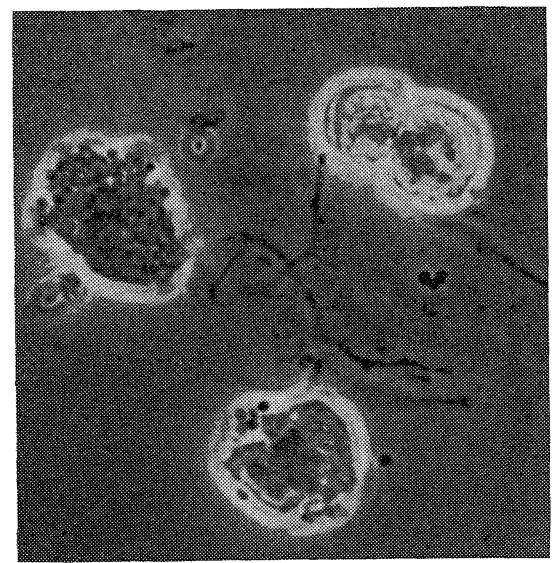

Plate 2. Actinoplanes brasiliensis. Sporangia developing on the surface of agar media. The highly irregular outer surface of the sporangia is evident $(\times 600 \times 1 / 1.5)$

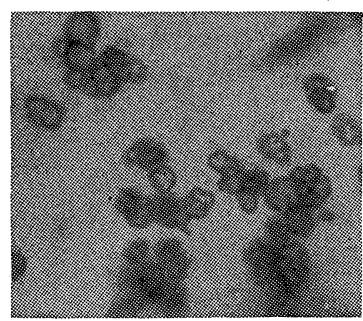

Plate 5. Actinoplanes philippinensis. Young, sphaerical and smooth walled sporangia forming on a vegetative hyphae

$$
(\times 1520 \times 1 / 1.5)
$$

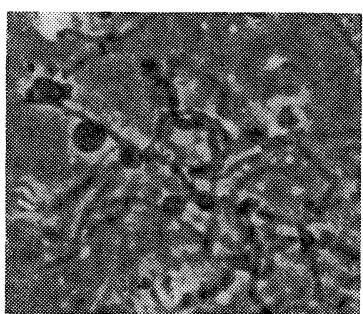

Plate 3. Actinoplanes philippinensis. Regular, smooth walled, sphaerical sporangia developing on the surface and also imbeded in the vegetative mycelium $\quad(\times 600 \times 1 / 1.5)$

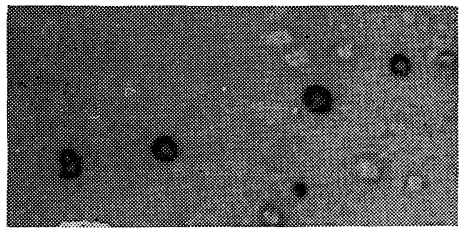

Plate 6. Actinoplanes brasiliensis. Flagellation of a motile sporangiospore

$(\times 1520 \times 1 / 1.5)$

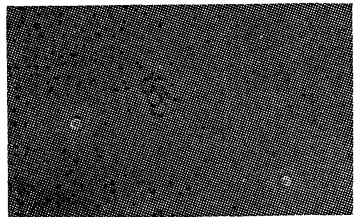

characteristic of the genus Actinoplanes. An exception to this rule can be found in Actinoplanes armeniacus. In this species the concomitant formation of aerial mycelium containing conidiospores and of sporangia emerging from the substrate mycelium and containing motile spores was described by Kalakoutski and KuzNetsov ${ }^{12)}$. The surface of culture $\mathrm{A} / 672$ is usually rough and its color ranging from light orange to intense orange. Soluble pigments are normally absent. Sporangium formation is very abundant on soil $\operatorname{agar}^{13)}$ and calcium malate agar. The sporangia of strain A/672 are irregular, club-shaped, but more frequently umbrella shaped (Plate 1) and very occasionally globose but always with a highly wrinkled surface (Plate 2). They were never observed to be imbeded in the vegetative mycelium as it frequently occurs with the sporangia of Actinoplanes philippinensis (Plate 3) in which the sporangia have also a characteristically smooth surface and are spherical to sub-globose (Plates 4,5 ). 
The size of the sporangia, measured at their widest side, varied from 3.5 to $11.5 \mu$. The sporangiophores are usually straight, however, occasionally wavy ones are found. They always grew into the air. They are $1.2 \mu$ wide and $4.5 \sim 1.5 \mu$ long, tending to enlarge versus the apex. The morphology of the spores varied from sub-spherical $(1.2 \mu)$ to rod shaped $(2.3 \times 1.2 \sim 1.7 \times 1.2 \mu)$. Due to the highly irregular sporangial morphology, an oriented Ampullariella-like pattern of spore disposition inside the sporangium is highly improbable. At least no clear-cut microscopic evidence could be obtained.

Spore dehiscence and motility initiates, in strain A/672, very vigorously a short time after the plates are flooded with water. Flagella staining ${ }^{16)}$ reveals the presence of short lophotrichous flagella (Plate 6). Spore liberation takes place by the unoriented rupture of the sporangium (Plate 7 ).

Immediately after mounting the sporangia in water between cover slides, the sporangial wall of strain A/672 is not clearly visible. Prior to the spore enclosure, however, the sporangial wall as well as the spores inside the sporangium become clearly differentiated. Approaching the sporangiospore liberation, the sporangia loose their irregular shape and become more uniform and sphaerical, very probably because

Table 2. Physiological characteristics of Actinoplanes A/672 and related microorganisms

\begin{tabular}{|c|c|c|c|c|}
\hline Test & Actinoplanes A/672 & A. missouriensis & A. utahensis & A. philifpinensis \\
\hline Starch hydrolysis & +++ & + & + & +++ \\
\hline $\mathrm{H}_{2} \mathrm{~S}$ formation & - & - & + & \pm \\
\hline Melanin & - & - & + & - \\
\hline Tyrosin hydrolysis & - & +++ & \pm & + \\
\hline Xanthine hydrolysis & - & - & - & - \\
\hline $\begin{array}{l}\text { Casein hydrolysis } \\
\quad \text { (Skim milk) }\end{array}$ & + & + & + & + \\
\hline Calcium malate hydrolysis & + & \pm & + & + \\
\hline Nitrate reduction & reduced & reduced & reduced & reduced \\
\hline Litmus milk & $\begin{array}{l}\text { no coagulation } \\
\text { no peptonization }\end{array}$ & $\begin{array}{l}\text { no coagulation } \\
\text { no peptonization }\end{array}$ & $\begin{array}{l}\text { no coagulation } \\
\text { no peptonization }\end{array}$ & $\begin{array}{l}\text { no coagulation } \\
\text { no peptonization }\end{array}$ \\
\hline Gelatine liquefaction & + & - & \pm & + \\
\hline
\end{tabular}

Table 3. Utilization of carbon compounds by strain A/672 and related species of Actinoplanes

\begin{tabular}{|c|c|c|c|c|}
\hline Carbon source & Strain A/672 & $\begin{array}{c}\text { Actinoplanes } \\
\text { philippinensis }\end{array}$ & $\begin{array}{c}\text { Actinoplanes } \\
\text { utahensis }\end{array}$ & $\begin{array}{l}\text { Actinoplanes } \\
\text { missouriensis }\end{array}$ \\
\hline Inositol & + & $+t$ & - & - \\
\hline Fructose & ++ & ++ & $+t$ & ++ \\
\hline Rhamose & ++ & ++ & ++ & ++ \\
\hline Mannitol & ++ & ++ & ++ & ++ \\
\hline Xylose & ++ & ++ & ++ & ++ \\
\hline Raffinose & - & ++ & - & - \\
\hline Arabinose & ++ & ++ & ++ & $+t$ \\
\hline Cellulose & + & + & - & - \\
\hline Sucrose & ++ & ++ & ++ & ++ \\
\hline Glucose (positive control) & $+t$ & ++ & ++ & ++ \\
\hline No carbon (negative control) & - & - & - & - \\
\hline
\end{tabular}

$++:$ Strongly positive utilization : growth is similar to or greater than growth on positive control.

$+:$ Positive utilization : growth is significantly greater than "no carbon" although somewhat less than on glucose.

- : Utilization negative : growth is similar to "no carbon" and much less than on positive control. 
of the swelling of the intrasporangial substance. Similar observations have also been made for A. utahensis (Couch, 1963).

Formation of palisade hyphae has not been observed. The vegetative mycelium is formed of long, wavy and twisted filaments, occasionally highly branched in the form of short lateral ramifications. The diameter of the hyphae varies from $0.6 \mu$ to $1.2 \mu$.

Appearance on various media.

The cultural and physiological characteristics of strain A/672 are listed respectively in Tables 1 and 2. The optimum temperature for development was tound to be from $28^{\circ}$ to $37^{\circ} \mathrm{C}$; no growth occurred at $45^{\circ} \mathrm{C}$.

The results of the carbon utilization test, performed according to SHIRLING and GotTLIEB $^{8)}$ are listed in Table 3.

\section{Isolation of Antibiotic A/672}

The product is of an acid nature and can be extracted with butanol from the fermentation broth acidified to $\mathrm{pH}$ 3.0. To achieve a preliminary purification the broth culture is first brought to $\mathrm{pH} 8.0$ and extracted with butanol. At this $\mathrm{pH}$ the antibiotic is completely soluble in water and the butanol containing some of the impurities is eliminated. The broth is then acidified ( $\mathrm{pH} 3.0$ ), re-extracted with butanol, washed with water to eliminate the excess of acid and concentrated to a small volume. The antibiotic is precipitated from the concentrated solution with an excess of petroleum ether. The product thus obtained can be further purified by reextracting into phenol from an aqueous solution, followed by a precipitation with an excess of acetone.

The antibiotic obtained is a whitish amorphous powder, acidic, highly soluble in water, soluble in methanol and dimethylformamide, poorly soluble in butanol, and insoluble in the higher alcohols, esters, acetone and chloroform.

Antibiotic A/672 shows UV absorption with a maximum at $265 \mathrm{~m} \mu$ in methanol, $0.1 \mathrm{~N} \mathrm{HCl}, 0.1 \mathrm{~N} \mathrm{NaOH}$ and $0.15 \mathrm{M}$ phosphate buffer at $\mathrm{pH} 7.38$ ( $\mathrm{E}_{\mathrm{cm}}^{1 \%} 103$ in methanol).

Fig. 1. Infrared spectrum of antibiotic $\mathrm{A} / 672$

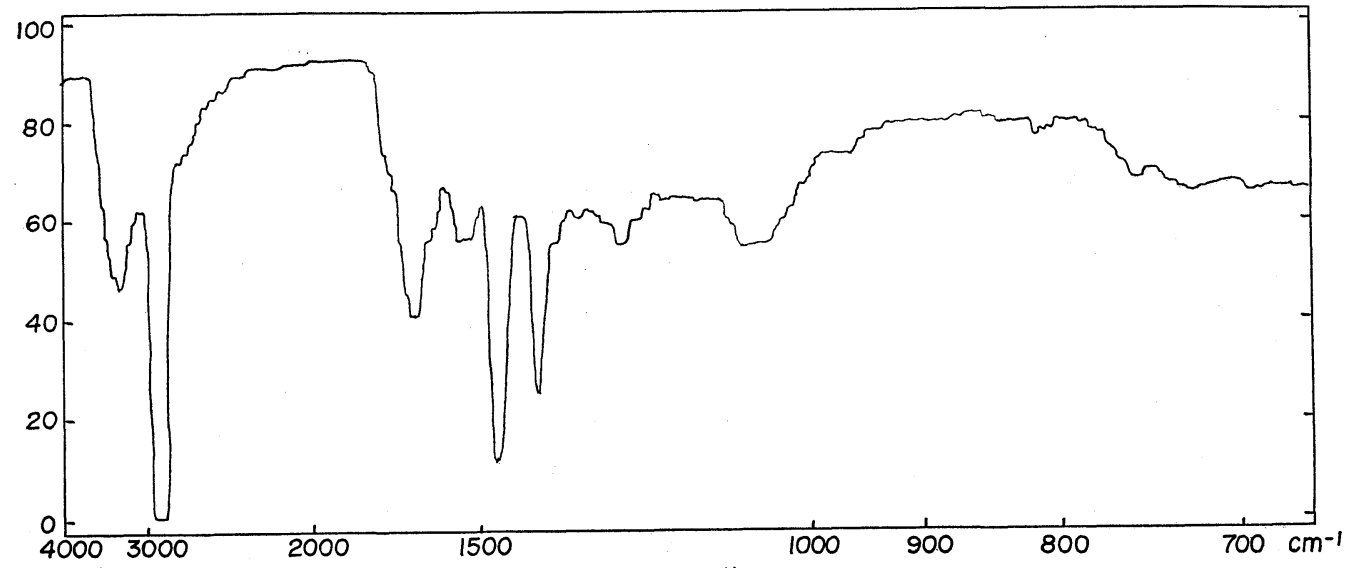


Table 4. Chromatographic pattern of antibiotic $\mathrm{A} / 672$ in various solvent systems

\begin{tabular}{|c|c|}
\hline Solvent system & $\operatorname{Rf} *$ \\
\hline Water-saturated $n$-butanol & 0.0 \\
\hline $\begin{array}{l}\text { Water-saturated } n \text {-butaonl containing } \\
2 \% p \text {-toluensulfonic acid }\end{array}$ & 0.0 \\
\hline $\begin{array}{l}\text { Water-saturated butanol containing } 2 \% \\
\text { concentrated ammonia }\end{array}$ & 0.05 \\
\hline n-Butanol-saturated water & 0.85 \\
\hline Ammonium chloride ( $20 \%$ solution in water) & 0.20 \\
\hline Phenol - water $(75: 25)$ & 0.90 \\
\hline $\begin{array}{l}\text { n-Butanol - methanol - water }(40: 10: 20) \\
\text { containing } 0.75 \mathrm{~g} \text { methyl orange }\end{array}$ & 0.20 \\
\hline$n$-Butanol - methanol - water $(40: 20: 20)$ & 0.20 \\
\hline Water - acetone $(1: 1)$ & 0.0 \\
\hline Water-saturated ethyl acetate & 0.0 \\
\hline
\end{tabular}

Table 5. Antimicrobial activity of antibiotic $\mathrm{A} / 672$

\begin{tabular}{|c|c|}
\hline Microorganisms & $\begin{array}{c}\mathrm{MIC} \\
(\mathrm{mcg} / \mathrm{ml}\end{array}$ \\
\hline Staphylococcus aureus 209 P, ATCC 6538 & 20 \\
\hline Staphylococcus aureus Tour* & 50 \\
\hline Streptococcus pyogenes C. 203 & 50 \\
\hline Streptococcus faecalis ATCC 10541 & $>100$ \\
\hline Diplococcus pneumoniae UC & 20 \\
\hline Proteus vulgaris X 19 ATCC 881 & $>100$ \\
\hline Escherichia coli ATCC 10536 & $>100$ \\
\hline Pseudomonas aeruginosa ATCC 10145 & $>100$ \\
\hline Candida albicans ATCC 10231 & $>100$ \\
\hline Trichophyton mentagrophites ATCC 8757 & $>100$ \\
\hline $\begin{array}{l}\text { Mycobacterium tuberculosis } \\
\qquad \mathrm{H}_{37} \mathrm{Rv} \text { ATCC } 9360\end{array}$ & $>100$ \\
\hline
\end{tabular}

* Clinical isolate.

The infrared spectrum is given in Fig. 1. Paper chromatography using different solvent systems followed by microbiological assay with Sarcina lutea gave only a single inhibition zone. The behavior of antibiotic $\mathrm{A} / 672$ in the different solvent systems is given in Table 4.

The antibiotic is active against Gram-positive bacteria but inactive against Gramnegative bacteria and fungi. Antibiotic A/672 showed no cross-resistance with the following antibiotics : cycloserine, gentamicin, oleandomycin, polymyxin, kanamycin, streptothricin, penicillin, rifamycin, bacitracin, tetracycline, lincomycin, erythromycin, cloramphenicol, streptomycin and neomycin. Its antibacterial spectrum is shown in Table 5. Using the intraperitoneal route an $\mathrm{LD}_{50}$ of approximately $300 \mathrm{mg} / \mathrm{kg}$ was obtained. No delayed toxicity was observed.

The in vivo activity was tested in mice against experimental infections using Streptococcus hemolyticus and Diplococcus pneumoniae. The product was administered subcutaneously for three consecutive days as a suspension in carboxymethyl-cellulose. A 100 per cent protection was obtained against D. pneumoniae at $100 \mathrm{mg} / \mathrm{kg}$.

\section{Discussion}

From the taxonomic studies performed it is evident that strain A/672 should be classified in the genus Actinoplanes. Comparative studies with three known species of this genus, Actinoplanes philippinensis, A. missouriensis and A. utahensis, showed that the color of the vegetative mycelium of strain A/672 did not differ very significantly from that of any of the known species.

The pigmentation of the vegetative mycelium in various shades of yellow seems to be a general characteristic of the genus Actinoplanes since this color is found in all the species so far described. Absorption spectra performed on the intra-mycelial pigments of three different genera of the Actinoplanaceae showed them to be identical ${ }^{15}$. Strain A/672 can be distinguished, however, from the known species by its morphological and biochemical characteristics.

Strain A/672 has large and highly irregular sporangia distinctly different from the sphaerical ones found in A. philippinensis and A. missouriensis. From these two species it can be further separated on the basis of its biochemical characteristics as can be seen in Tables 2 and 3 . 
With $A$. utahensis, strain $\mathrm{A} / 672$ has in common the highly irregular shape of the sporangia but differs from that culture by the inability to form hydrogen sulfide, melanoid pigments and tyrosine hydrolysis, three important characters for which $A$. utahensis gives positive results (Tables 2 and 3). The characteristically moist and glistening colony surface of $A$. utahensis on some culture media further differentiate these two cultures (Table 1).

In view of the above characteristics strain $\mathrm{A} / 672$ was considered to be a new species of the genus Actinoplanes for which the name Actinoplanes brasiliensis is proposed.

\section{Acknowledgments}

The authors wish to thank Drs. Arioli and Serralunga for the in vivo tests, and Drs. Pelizza and Pallanza respectively for the chromatographic and in vitro data.

\section{References}

1) Okuda, T.; Y. Iтo, T. Yamaguchi, T. Furumai, M. Suzuki \& M. Tsuruoka : Sporaviridin, a new antibiotic produced by Streptosporangium viridogriseum nov. sp. J. Antibiotics, Ser. A $19: 85 \sim$ 87, 1966

2) Thiemann, J. E.; C. Coronelli, H. Pagani, G. Beretta, G. Tamoni \& V. Arioli : Antibiotic production by new form-genera of the Actinomycetales. I. Sporangiomycin, an antibacterial agent isolated from Planomonospora parontospora var. antibiotica var. nov. J. Antibiotics 21 : 525 531, 1968

3) Thiemann, J. E.; H. Pagani \& G. Beretta : A new genus of the Actinoplanaceae : Planomonospora gen. nov. Giorn. Microbiol. $15: 27 \sim 38,1967$

4) Nonomura, H. \& Y. Ohara: Distribution of the Actinomycetes in soil. V. The isolation and classification of the genus Streptosporangium. (in Japanese) J. Ferment. Technology $38: 405$ $\sim 409,1960$

5) Taig, M. M.; S. M. Rudaya \& N. K. Solovieva : Cultures of Actinomycetes of the Actinoplanaceae family. Antibiotiki (USSR) $7: 483 \sim 491,1962$

6) Cross, T.; M. P. Lechevalier \& H. Lechevalier: A new genus of the Actinomycetales : Microellobosporia gen. nov. J. Gen. Microbiol. $31: 421 \sim 430,1963$

7) Koniev, Yu. E.; V. A. Tsiganov, R. Minbaiev \& V. M. Morosov: A new genus of the Actinomycetales : Microechinospora gen. nov. Mikrobiologyia $36: 309 \sim 317,1967$

8) Shirling, E. B. \& D. Gottlieb : Methods for characterization of Streptomyces species. Intern. J. Syst. Bact. 16 : 313 340, 1966.

9) Waksman, S. A. : The Actinomycetes. vol. II. The Williams \& Wilkins Co., 1961

10) Couch, J. N. : Actinoplanes, a new genus of the Actinomycetales. J. Elisha Mitchell Sci. Soc. $66: 87 \sim 92,1950$

11) Couch, J. N. : Some new genera and species of the Actinoplanaceae. J. Elisha Mitchell Sci. Soc. $79: 53 \sim 70,1963$

12) Kalakoutsski, L. V. \& V. D. Kuznetsov: A new species of the genus Actinoplanes Couch, Actinoplanes armeniacus, n. sp., and some peculiarities of its mode of spore formation. Mikrobiologiya $33: 613 \sim 621,1964$

13) Thiemann, J. E.; H. Pagani \& G. Beretta : A new genus of the Actinoplanaceae : Dactylosporangium gen. nov. Arch. Mikrobiol. $58: 42 \sim 52,1967$

14) Maerz, A. \& M. Rea PaUl : A dictionary of color. McGraw-Hill Inc., New York, 1950

15) Kane, W. D. : A new genus of Actinoplanaceae, Pilimelia, with a description of two species, Pilimelia terevasa and Pilimelia anulata. J. Elisha Mitchell Sci. Soc. $82: 220 \sim 230,1966$

16) Leifson, E. : Staining, shape and arrangement of bacterial flagella. J. Bact. $62: 377 \sim 389,1951$ 